\title{
A Variable $\mathrm{CD}^{+} \mathrm{T}$-Cell Frequency in Peripheral Blood Lymphocytes Associated with Type 1 Diabetes Mellitus Development in the LEW.1AR1-iddm Rat
}

\author{
Tanja Arndt ${ }^{1,2}$, Anne Jörns ${ }^{1,3}$, Heike Weiss ${ }^{1,4}$, Markus Tiedge ${ }^{1,4}$, Hans-Jürgen Hedrich ${ }^{2}$, Sigurd Lenzen ${ }^{1}$, \\ Dirk Wedekind ${ }^{2 *}$
}

1 Institute of Clinical Biochemistry, Hannover Medical School, Hannover, Germany, 2 Institute for Laboratory Animal Science, Hannover Medical School, Hannover, Germany, $\mathbf{3}$ Centre of Anatomy, Hannover Medical School, Hannover, Germany, 4 Institute of Medical Biochemistry and Molecular Biology, University of Rostock, Rostock, Germany

\begin{abstract}
Purpose: The LEW.1AR1-iddm rat is an animal model of human type 1 diabetes mellitus (T1DM), which arose through a spontaneous mutation within the MHC-congenic inbred strain LEW.1AR1 $\left(R T 1^{r 2}\right)$. In contrast to the diabetes-resistant LEW.1AR1 background strain in LEW.1AR1-iddm rats a highly variable T-cell frequency could be observed in peripheral blood lymphocytes (PBLs).

Methods: In this study we therefore characterised the T-cell repertoire within the PBLs of the two strains by flow cytometry analysis and identified the $\mathrm{CD}^{+} \mathrm{T}$-cell phenotype and its possible linkage to diabetes susceptibility. To map loci conferring susceptibility to variable $\mathrm{CD}^{+}$T-cell frequency, backcross strains (N2) were generated with the genetically divergent BN and PAR rats for microsatellite analysis.

Results: The LEW.1AR1-iddm rat strain was characterised by a higher variability of CD3 ${ }^{+}$T-cells in PBLs along with a slightly decreased mean value compared to the LEW.1AR1 background strain. The reason for this reduction was a decrease in the $\mathrm{CD}^{+} \mathrm{T}$-cell count while the $\mathrm{CD} 8^{+} \mathrm{T}$-cell proportion remained unchanged. However, both T-cell subpopulations showed a high variability. This resulted in a lower $\mathrm{CD} 4^{+} / \mathrm{CD}^{+} \mathrm{T}$-cell ratio than in LEW.1AR1 rats. Like LEW.1AR1-iddm rats all animals of the backcross populations, N2 BN and N2 PAR rats, also showed large variations of the CD3 ${ }^{+}$T-cell frequency. The phenotype of variable $\mathrm{CD}^{+}$T-cell frequency mapped to the telomeric region of chromosome 1 (RNO1), which is identical with the already known $I d d m 8$ diabetes susceptibility region. The data indicate that a variable $\mathrm{CD}^{+} \mathrm{T}$-cell frequency in PBLs is genetically linked to diabetes susceptibility in the LEW.1AR1-iddm rat.

Conclusion: The T-cell variability in PBLs could be related to the previously reported imbalance between regulatory and effector T-cell populations which results in beta-cell autoimmunity. Since similar T-cell phenotypes have also been described in human T1DM the identification of the functional role of the observed variable $\mathrm{CD}^{+}{ }^{+}$-cell frequency may help to understand the mechanisms of autoimmunity in T1DM.
\end{abstract}

Citation: Arndt T, Jörns A, Weiss H, Tiedge M, Hedrich H-J, et al. (2013) A Variable CD3 ${ }^{+}$T-Cell Frequency in Peripheral Blood Lymphocytes Associated with Type 1 Diabetes Mellitus Development in the LEW.1AR1-iddm Rat. PLoS ONE 8(5): e64305. doi:10.1371/journal.pone.0064305

Editor: Kathrin Maedler, University of Bremen, Germany

Received January 21, 2013; Accepted April 14, 2013; Published May 22, 2013

Copyright: (C) 2013 Arndt et al. This is an open-access article distributed under the terms of the Creative Commons Attribution License, which permits unrestricted use, distribution, and reproduction in any medium, provided the original author and source are credited.

Funding: This work has been supported by grants from the Deutsche Forschungsgemeinschaft to AJ and the European Union (Collaborative Project NAIMIT in the 7th Framework Programme, Contract No. 241447) to SL. The funders had no role in study design, data collection and analysis, decision to publish, or preparation of the manuscript.

Competing Interests: The authors have declared that no competing interests exist.

*E-mail: wedekind.dirk@mh-hannover.de

\section{Introduction}

Type 1 diabetes mellitus (T1DM) is a multifactorial disease in which a predisposing genetic background as well as environmental factors ultimately lead to an autoimmune destruction of the pancreatic beta cells [1]. Animal models play an important role for the understanding of the pathogenesis of T1DM because they permit combining genetic and functional characterisation of the syndrome [2]. The LEW.1AR1-iddm rat is a model for human T1DM, which arose through a spontaneous mutation in the intra-MHC recombinant inbred strain LEW.1AR1 $\left(R T 1^{r 2}, R T 1-A^{a}, R T 1-B / D^{u}, R T 1-C^{u}\right)$ [3]. This model shows an apoptotic beta-cell destruction, induced by proinflammatory cytokines released from islet infiltrating immune cells [4]. The autoimmune nature of the diabetic syndrome has been proven by adoptive transfer experiments $[5,6]$.

The diabetic syndrome of the LEW.1AR1-iddm rat follows an autosomal recessive mode of inheritance with an incomplete penetrance of the mutant phenotype of about $60 \%$ [3,4]. Three T1DM susceptibility loci in the LEW.1AR1-iddm model have been discovered by genome wide linkage analysis using a $[(\mathrm{BN} \times \mathrm{LE}$ W.1AR1-iddm) $\times$ LEW.1AR1-iddm] N2 (N2 BN) population [7]. One locus mapped to RNO20p12 within the MHC (Major Histocompatibility Complex) region which provides T1DM susceptibility also in humans (IDDMI), the NOD mouse (Idd1), the BB rat and the KDP 
rat models (Iddm I) [8]. Thus, the MHC haplotype plays a pivotal role in permitting T1DM development [9].

In the LEW.1AR1-iddm rat two further $I d d m$ loci reside on RNO1. The $I d d m 8$ locus was discovered within RNO1q51-55 at the telomeric end and Iddm9 could be localized in RNOlp11lq11 near the centromer using the N2 BN backcross population. In an additional [(PAR $\times$ LEW.1AR1-iddm $) \times$ LEW.1AR1-iddm] N2 (N2 PAR) population the $I d d m 1$ and $I d d m 8$ loci could be confirmed in this genetically divergent strain [10].

The LEW.1AR1-iddm rats show mean values of $\mathrm{CD} 3^{+} \mathrm{T}$-cells in peripheral blood around $50 \%$ by flow cytometric analysis [3]. In the present study the detailed analysis of immune cells in peripheral blood indicated that LEW.1AR1-iddm rats compared to the diabetes-resistant LEW.1AR1 background strain showed a slight decrease of the mean value of around $10 \%$ (non-diabetic LEW.1AR1-iddm rats) and 20\% (diabetic LEW1AR1-iddm rats) and a more variable $\mathrm{CD} 3^{+} \mathrm{T}$-cell frequency than the background strain. The phenotype of the 'variable $\mathrm{CD}^{+}{ }^{+} \mathrm{T}$-cell frequency' was characterized and the responsible locus for this trait could be mapped within Iddm 8 in two $\mathrm{N} 2$ cohorts generated with the genetically divergent $\mathrm{BN}$ and PAR strains. Our data provide evidence that the mutation within the $I d d m 8$ region on RNO1 not only confers susceptibility to T1DM but also to the variable $\mathrm{CD} 3^{+}$ $\mathrm{T}$-cell frequency in blood.

\section{Materials and Methods}

\section{Animals}

All rats were housed under specific pathogen free (SPF) conditions in the same hygiene unit at the Central Animal Facility of Hannover Medical School (Ztm). They were regularly monitored for infection by typical viral pathogens and were shown to be serologically negative for Hanta, Kilham rat, PVM, Reo3, Sendai, SDA, rat corona, Theiler's encephalomyelitis, and Toolan's (H1) viruses [3,11]. The rats were held in groups of three animals under a 14:10 light-dark cycle, $55 \pm 5 \%$ humidity, in type IV Makrolon cages (Techniplast, Hohenpeißenberg, Germany) on a standard softwood bedding (Altromin 3/4), with free access to sterilised standard laboratory chow (diet No. 1324, Altromin, Lippe, Germany) and water.

The following strains were analysed by flow cytometry: LEW.1AR1-iddm ( $\mathrm{n}=34$ diabetic; $\mathrm{n}=32$ non-diabetic), LEW.1AR1 $(\mathrm{n}=12), \mathrm{BN}(\mathrm{n}=10)$ and PAR $(\mathrm{n}=8)$ and all generated crosses as described (F1 BN: $n=6$; N2 BN: $n=155$; F1 PAR: $\mathrm{n}=12$; N2 PAR: $\mathrm{n}=151)$. Blood was taken from all animals at an age between 35-110 days (from LEW.1AR1-iddm rats and N2 rats after diabetes onset, from non-diabetic LEW.1AR1-iddm, F1 and N2 rats between day 90 and 110 and from the background strain LEW.1AR1 between day 35 and 110). BN and PAR backcross populations were generated as described below. F1 animals were generated by mating diabetic male LEW.1AR 1-iddm rats with female BN $\left(R T 1^{n}\right)$ and PAR $\left(R T 1^{g}\right)$ rats to analyse the LEW.1AR1$i d d m$ rat for susceptibility loci for the variable $\mathrm{CD}^{+}$T-cell frequency. Notably, none of the $\mathrm{BN}$ rats or PAR rats developed diabetes. The female offspring of the intercrosses (LEW.1AR1$i d d m \times \mathrm{BN}) \mathrm{F} 1$ and (LEW.1AR 1-iddm $\times$ PAR) F1 was backcrossed to diabetic male LEW.1AR1-iddm rats. N2 BN and N2 PAR animals were genotyped by microsatellite analysis. Blood glucose concentrations were checked twice weekly until day 120 of life (Glucometer Elite $^{\mathrm{TM}}$, Bayer, Leverkusen, Germany). Diabetic animals were sacrificed within $48 \mathrm{~h}$ after onset of hyperglycemia ( $\geq 10 \mathrm{mmol} / \mathrm{l}$ ) for preparation of genomic DNA from tail, ear, spleen, and thymus. The same procedure was applied to nondiabetic animals at the age of 120 days.
Experimental procedures were performed according to the German Animal Welfare Act (Tierschutzgesetz, § 4) and approved by the Local Institutional Animal Care and Research Advisory Committee of Hannover Medical School and the Lower Saxony State Office for Consumer Protection and Food Safety (Approval ID: $42500 / 1 \mathrm{H})$.

\section{Pancreas Morphology}

All pancreases of the diabetic and non-diabetic animals of the different strains and cross populations were analysed morphologically for immune cell infiltration. Independent from the changes in the $\mathrm{CD}^{+}$T-cell frequency in PBLs (peripheral blood lymphocytes) the pancreatic islets of all diabetic animals were severely infiltrated by $\mathrm{T}$-cells and macrophages as main immune cell types. The pancreatic islets from the non-diabetic animals remained unaffected.

\section{DNA Preparation}

Genomic DNA was extracted from the tissues using the NucleoSpin ${ }^{\mathrm{TM}}$ Tissue kit (Macherey-Nagel, Düren, Germany) according to the manufacturer's instructions.

\section{Flow Cytometry}

In order to determine the different lymphocyte subpopulations in peripheral blood flow cytometric analyses were performed using the following labelled monoclonal antibodies: CD3 (G4.18) PE, CD4 (OX-38) FITC, (Becton Dickinson, Heidelberg, Germany); CD8 (OX-8) FITC, CD8 (OX-8) PE, (Serotec, Düsseldorf, Germany). $50 \mu \mathrm{l}$ blood were prepared for immune cell analysis by $2-3 \times$ lysis in $2 \mathrm{ml}$ lysis buffer $\left(160 \mathrm{mmol} \mathrm{NH}_{4}, 0.1 \mathrm{mmol}\right.$ EDTA, $\left.12 \mathrm{mmol} \mathrm{NaHCO}_{3}\right)$ and centrifuged $(200 \times \mathrm{g})$ for $4 \mathrm{~min}$ each. Thereafter, the cell pellet was washed twice with FACS buffer (phosphate buffered saline, $0.03 \%$ sodium azide, $0.1 \%$ bovine serum albumin) and centrifuged again. The pellet was resuspended in $20 \mu \mathrm{l}$ diluted antibody solution and incubated for $30 \mathrm{~min}$ at $4^{\circ} \mathrm{C}$. After washing the cells twice with $2 \mathrm{ml}$ FACS buffer the cell pellet was resuspended in $200 \mu \mathrm{l}$ FACS buffer and measured in a flow cytometer (Becton Dickinson). Cell characteristics (size and granularity) and antibody staining of living cells were assessed. Data processing was carried out using the Cellquest 3.0.1 Software. A gate for lymphocytes was created based on size and granularity of peripheral blood cells.

\section{Microsatellite Analyses}

All oligonucleotide primers used in this study were developed and used as described previously for genome wide mapping of the phenotype 'diabetes' $[7,10]$. The PGR reaction was performed according to manufacturer's instructions (Peqlab Biotechnologie, Erlangen, Germany) with $100 \mu \mathrm{g}$ DNA template per well in a 96well plate (MultiRigid Ultra Plates ${ }^{\mathrm{TM}}$, Roth, Karlsruhe, Germany) using a PTC-200 thermocycler (Biozym, Hess. Oldendorf, Germany). The PCR conditions were $4 \mathrm{~min}$ at $94^{\circ} \mathrm{C}$; 35 cycles: $15 \mathrm{~s}$ at $94^{\circ} \mathrm{C}, 1 \mathrm{~min}$ at $55^{\circ} \mathrm{C}$ with the exception of $\mathrm{D} 12 \operatorname{tm} 1\left(57^{\circ} \mathrm{C}\right)$ and $D 1 Z t m 2\left(53.2^{\circ} \mathrm{C}\right), 2 \mathrm{~min}$ at $72^{\circ} \mathrm{C} ; 7 \mathrm{~min}$ final extension at $72^{\circ} \mathrm{C}$. PCR products were analysed by electrophoresis in $3 \%$ NuSieve ${ }^{\mathrm{TM}}$ agarose gels (Biozym, Hess. Oldendorf, Germany). Gels were stained using Gelstar ${ }^{\text {TM }}$ (Cambrex, Apen, Germany) and documented by UV light illumination at $312 \mathrm{~nm}$.

\section{Statistical Analyses}

Linkage analysis was performed using the JoinMap V 2.0 program (Agricultural Research Dept., Wageningen, Netherlands). The LOD (logarithm of the odds) scores of the susceptibility 
regions for the variable $\mathrm{T}$-cell frequency were calculated using the $\mathrm{R}$ /qtl program kindly provided by Dr. K. Browman (Dept. of Biostatistics, Johns Hopkins University, Baltimore, MD) as used before for identification of the mutation in other disease models [12-15]. E/M algorithms estimated susceptibility regions in a binary model using the $\mathrm{CD}^{+} \mathrm{T}$-cell frequency ( $\mathrm{T}$-cell frequency $>70 \%$ and $<40 \%$ ) of the animals as a trait. A permutation test was performed to calculate the threshold value for significance (LOD score >2.3) [16]. Statistical analysis of flow cytometry (mean values, ANOVA plus Tukey's post test and coefficient of variation $(\mathrm{CV})$ ) was calculated using GraphPad Prism 5 software.

\section{Results}

Frequency of T-cells in PBLs in the LEW.1AR1-iddm (Diabetic and Non-diabetic) Rats and the Background Strain LEW.1AR1

The percentage of $\mathrm{CD}^{+}{ }^{+}$T-cells in PBLs within the LEW.1AR1 background population varied between $63 \%$ and $74 \%$ (mean \pm SEM: $69 \pm 1 \%, \mathrm{CV}$ (coefficient of variation): 5.3) (Fig. 1A). In contrast, the variability of the T-cell frequency in PBLs within the diabetic and non-diabetic LEW.1AR1-iddm population was higher than in the LEW.1AR1 strain. Significant differences of the average percentage could be detected not only between the inbred strains LEW.1AR1 and LEW.1AR1-iddm, but also between the diabetic and the non-diabetic LEW.1AR1-iddm group (Fig. 1A). The percentage of $\mathrm{CD} 3^{+}$T-cells in PBLs within the diabetic LEW.1AR 1-iddm group was in the range of $34 \%$ to $63 \%(51 \pm 1 \%$, $\mathrm{p}<0.001, \mathrm{GV}: 15.8$ ), while within the non-diabetic LEW.1AR1$i d d m$ group this value varied between $36 \%$ and $80 \%(59 \pm 2 \%$, $\mathrm{p}<0.02, \mathrm{CV}: 22.9)$. Additionally, a significant decrease of the $\mathrm{CD} 3^{+}$T-cells could be observed in the diabetic LEW.1AR1-iddm group as compared to the non-diabetic LEW.1AR1-iddm group $(\mathrm{p}<0.001)$, but the variability in both groups was comparable.

In LEW.1AR1 rats the percentage of $\mathrm{CD} 4^{+}$T-cells in PBLs varied within a narrow range between $42 \%$ and $51 \%(46 \pm 1 \%$, GV: 6.0) (Fig. 1B). In contrast, diabetic and non-diabetic LEW.1AR1-iddm rats exhibited not only a higher variability but also a lower percentage of $\mathrm{CD}^{+}$T-cells in PBLs. Notably, these differences were also observed between the diabetic and the nondiabetic LEW.1AR1-iddm rats (Fig. 1B). The percentage of CD4 ${ }^{+}$ T-cells in PBLs in the diabetic LEW.1AR1-iddm group was in the range of $10 \%$ to $45 \%(30 \pm 1 \%, \mathrm{p}<0.001, \mathrm{CV}$ : 23.0$)$, while the frequency of $\mathrm{CD}^{+}$T-cells in PBLs within the non-diabetic LEW.1AR 1-iddm group varied between $19 \%$ and $52 \%(36 \pm 2 \%$, $\mathrm{p}<0.001, \mathrm{CV}$ : 28.3). A significant decrease of $\mathrm{CD}^{+}{ }^{+} \mathrm{T}$-cells could be also observed between the diabetic LEW.1AR1-iddm cohort and the non-diabetic LEW.1AR1-iddm cohort $(\mathrm{p}<0.02)$ with comparable variability.

The percentage of $\mathrm{CD}^{+}{ }^{+} \mathrm{T}$-cells in PBLs within the LEW.1AR 1 control cohort showed a low variability between $20 \%$ and $25 \%$ (22 $\pm 0 \%$, CV: 6.9) (Fig. 1C). In contrast, the variability of the Tcell frequency in PBLs within the diabetic and non-diabetic LEW.1AR1-iddm population was very high but significant differences of the mean percentage could not be detected between LEW.1AR1 and both diabetic and non-diabetic LEW.1AR1-iddm rats (Fig. 1C). The percentage of CD8 ${ }^{+}$T-cells in PBLs within the diabetic LEW.1AR1-iddm group was in a range between 3\% and $27 \%$ (19 $\pm 1 \%$, CV: 30.4 ), while the frequency of $\mathrm{CD}^{+} \mathrm{T}$-cells in PBLs within the non-diabetic LEW.1AR1-iddm group varied between $12 \%$ and $44 \%(23 \pm 1 \%$, CV: 34.8$)$. A significant decrease of $\mathrm{CD}^{+}$T-cells could only be observed in the diabetic LEW.1AR1-iddm group compared to the non-diabetic LE-
W.1AR1-iddm group $(\mathrm{p}<0.02)$ with similar variability in both groups.

\section{Ratio of $\mathrm{CD}^{+} / \mathrm{CD}^{+}$T-cells in PBLs of LEW.1AR1 and LEW.1AR1-iddm Rats}

Because of the variability in each single animal it was necessary to calculate the $\mathrm{CD}^{+} / \mathrm{CD}^{+} \mathrm{T}$-cell ratio for each animal. From these a mean value was calculated for the $\mathrm{CD}^{+} / \mathrm{CD}^{+} \mathrm{T}$-cell ratio of each animal group.

The $\mathrm{CD}^{+} / \mathrm{CD}^{+}$T-cell ratio in PBLs of diabetes resistant LEW.1AR1 rats was on average 2.1 \pm 0.1 (Fig. 1D). The diabetic LEW.1AR1-iddm group had a significantly lower $\mathrm{CD}^{+} / \mathrm{CD}^{+} \mathrm{T}$ cell ratio within PBLs $(1.5 \pm 0.1, \mathrm{p}<0.001)$ with a higher variability (1.0 to 2.1, GV: 22.4) compared to the LEW.1AR1 background strain (2.1 \pm 0.3 , GV: 4.8) (Fig. 1D). The non-diabetic LEW.1AR1$i d d m$ rats also showed a significantly lower $\mathrm{CD}^{+} / \mathrm{CD}^{+}$T-cell ratio $(1.7 \pm 0.1, \mathrm{p}<0.001)$ with a higher variability $(0.9$ to $2.2, \mathrm{CV}$ : 17.3) compared to the background strain. But there was no difference in the variability of the $\mathrm{CD} 4^{+} / \mathrm{CD}^{+} \mathrm{T}$-cell ratio in PBLs between diabetic and non-diabetic LEW.1AR1-iddm rats. Interestingly, the $\mathrm{CD}^{+} / \mathrm{CD}^{+}{ }^{+} \mathrm{T}$-cell ratio was significantly higher in non-diabetic LEW.1AR 1-iddm rats $(1.7 \pm 0.1, \mathrm{p}<0.05)$ than in diabetic LEW.1AR 1-iddm rats $(1.5 \pm 0.1)$.

\section{Distribution and Inheritance of the $\mathrm{CD}^{+} \mathrm{T}$-cell Frequency in PBLs within Different Rat Inbred Strains, Intercrosses (F1) and Backcrosses (N2)}

As described before, the variance of the $\mathrm{CD}^{+}{ }^{+} \mathrm{T}$-cell frequency in PBLs within the cohort of the mutated LEW.1AR1-iddm rats (CV: 21.4) was significantly higher than that of the LEW.1AR 1 group (CV: 5.2, p $<0.01$, Fig. 2A). The mean of the $\mathrm{CD}^{+}{ }^{+}$-cell frequency in the F1 animals of a (LEW.1AR1-iddm $\times$ LEW.1AR1) cross as well as the variability $(69 \pm 2 \%, \mathrm{CV}$ : 7.2) did not differ from the background strain LEW.1AR1, indicating an autosomal recessive mode of inheritance.

Although the inbred strains LEW.1AR1, BN, and PAR differed in their average $\mathrm{CD}^{+}{ }^{-} \mathrm{T}$-cell frequency within PBLs the variability of the $\mathrm{CD} 3^{+} \mathrm{T}$-cell frequency was comparatively low in these three strains (LEW.1AR1:69 $\pm 1 \%, \mathrm{CV}: 5.2$; BN: $38 \pm 1 \%, \mathrm{CV}: 8.3$; PAR: $52 \pm 2 \%, \mathrm{CV}: 9.0)(\mathrm{p} \geq 0.5)$. Also the intercrosses $(\mathrm{BN} \times \mathrm{LE}-$ W.1AR1-iddm) F1 and (PAR $\times$ LEW.1AR1-iddm) F1 did not differ significantly from $\mathrm{BN}$ and $\mathrm{PAR}$ strains, respectively in the variability of the $\mathrm{CD} 3^{+} \mathrm{T}$-cell frequency $(\mathrm{p} \geq 0.5)$. The frequency of $\mathrm{CD}^{+}{ }^{+}$T-cells in PBLs in the (BN $\times$LEW.1AR1-iddm) $\mathrm{F} 1$ progeny was $46 \pm 3 \%$ (CV: 12.4) (Fig. 2B) and in the (PAR $\times$ LEW.1AR1iddm) $\mathrm{F} 1$ progeny $46 \pm 2 \%$ (CV: 11.7) (Fig. 2C). The frequency and the variance in both $\mathrm{F} 1$ cohorts did not differ significantly from the BN and PAR rats but it did from the LEW.1AR1-iddm rats, indicating a recessive mode of inheritance again.

For mapping the causative mutation a [BN $\times$ LEW.1AR1-iddm) $\times$ LEW.1AR1-iddm $]$ N2 (N2 BN) population and a $[$ PAR $\times$ LEW.1AR1-iddm) $\times$ LEW.1AR1-iddm] N2 (N2 PAR) population were generated. According to the Mendelian rules it could be expected that $50 \%$ of the $\mathrm{N} 2$ population display a change in the T-cell frequency (mean values, variability) in the PBLs. In fact, the percentage of T-cells varied between 26 and $72 \%$ with a mean of $44 \pm 2 \%(\mathrm{CV}: 20.2)$ in the $\mathrm{N} 2 \mathrm{BN}$ population and between 21 and $76 \%$ with a mean of $40 \pm 1 \%$ (CV: $25.96 \%$ ) in the N2 PAR population (Fig. 2B and Fig. 2C). In both cases the GV differed significantly $(\mathrm{p}<0.03)$ from the $\mathrm{F} 1$ population and was identical to that of the LEW.1AR1-iddm rats. 

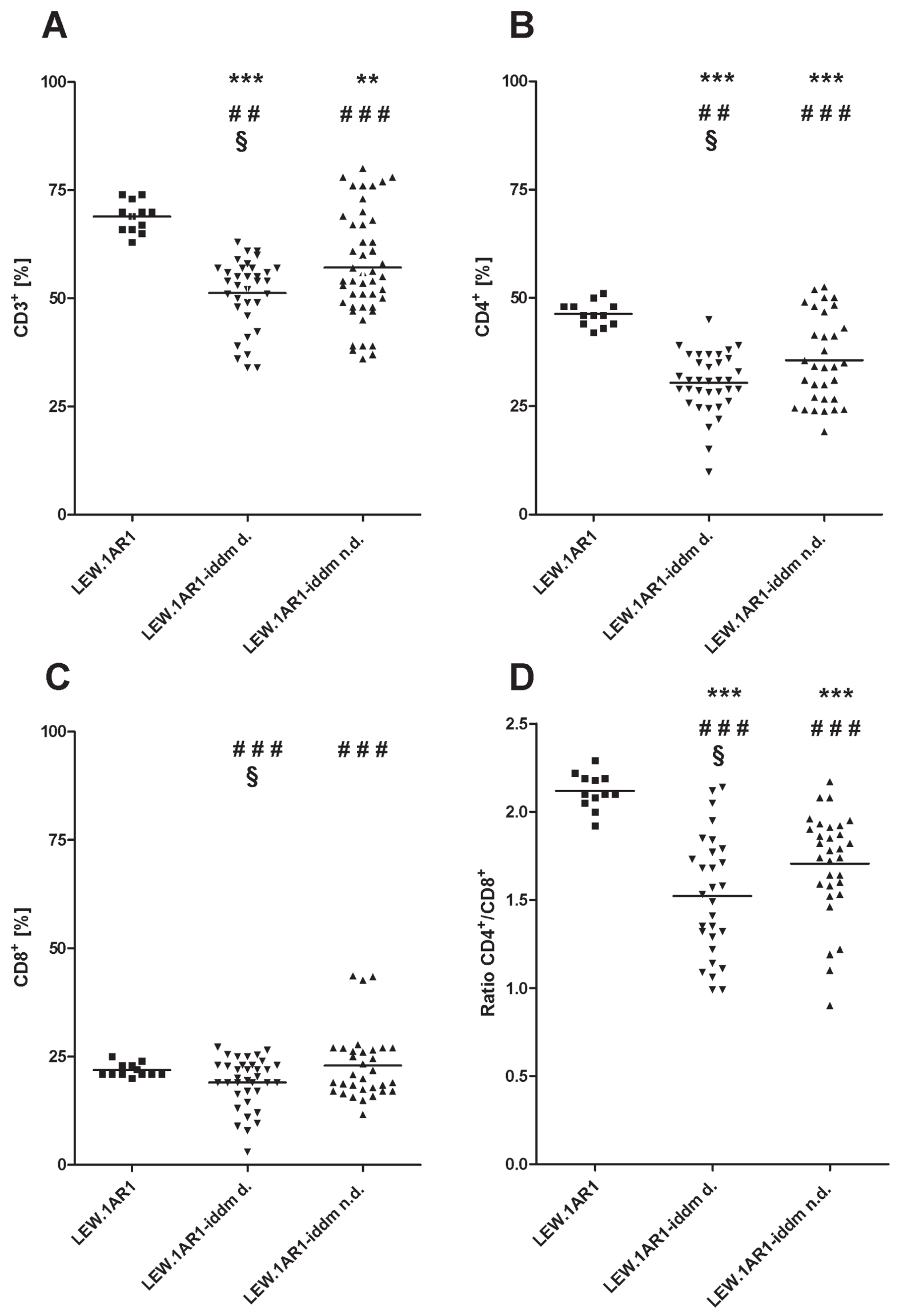
Figure 1. The percentages of T-cell subpopulations within PBLs of LEW.1AR1 and LEW.1AR1-iddm rats (d.=diabetic animals; n.d. = non-diabetic animals). The percentages of $(A) \mathrm{CD}^{+},(B) C D 4^{+},(C) C D 8^{+} \mathrm{T}$-cells, and (D) $\mathrm{CD} 4^{+} / \mathrm{CD} 8^{+} \mathrm{T}$-cell ratio were determined in PBLs by flow cytometric analysis from rats at an age between 35 and 110 days. Each symbol represents the T-cell value for a single animal. The number of animals was for LEW.1AR1 $(n=12)$, LEW.1AR1-iddm diabetic $(n=34)$ and LEW.1AR1-iddm non-diabetic $(n=32)$. The mean values for the different groups are represented by the horizontal bar in the graphs and were compared statistically. ${ }^{* *} p<0.01 /{ }^{* * *} p<0.0001$ LEW.1AR1 compared to LEW.1AR1-iddm, ${ }^{\S} \mathrm{p}<0.05$ diabetic compared to non-diabetic LEW.1AR1-iddm rats, and ${ }^{\# \#} \mathrm{p}<0.01 /{ }^{\# \# \#} \mathrm{p}<0.0001$ for range of percentage LEW.1AR1 group compared to LEW.1AR1-iddm group, (ANOVA plus Tukey's post test).

doi:10.1371/journal.pone.0064305.g001

\section{Association of Microsatellite Markers with Diabetes} Manifestation and $\mathrm{CD}^{+}$T-cell Frequency in PBLs

We mapped the phenotype of the variable $\mathrm{CD}^{+}$T-cell frequency in the LEW.1ARl-iddm strain using 157 informative markers with an intermarker distance of about $20 \mathrm{cM}$ over the whole genome $[7,10]$. In the region of interest on RNO1 a denser mapping was performed using microsatellite markers with an intermarker distance of about $1 \mathrm{cM}$.

Linkage analysis of the trait 'variable $\mathrm{CD} 3^{+} \mathrm{T}$-cell frequency' in a N2 BN cohort identified one susceptibility locus on RNO1 (Fig. 3A, dotted line), while for the trait 'T1DM' two susceptibility loci could be mapped on RNO1, Iddm 8 and Iddm 9 (Fig. 3A, solid line) [7]. The peak of this locus of the variable $\mathrm{CD}^{+} \mathrm{T}$-cell frequency was located within the already identified $I d d m 8$ region at the telomeric end of RNOl at about $145 \mathrm{cM}$ (Fig. 3A, dotted line). The linkage analysis of an N2 PAR population showed only one T1DM susceptibility locus in the rat, overlapping with Iddmo (Fig. 3B, solid line) [10]. In this N2 PAR population the peak of the locus of the trait 'variable $\mathrm{CD} 3^{+} \mathrm{T}$-cell frequency' could also be mapped within the $I d d m 8$ region on the telomeric end of RNOl at about $120 \mathrm{cM}$ (Fig. 3B, dotted line). Thus there is a clear overlap between the susceptibility loci for T1DM manifestation and variable $\mathrm{CD} 3^{+} \mathrm{T}$-cell frequency.

\section{Discussion}

The present study was prompted by the observation that the LEW.1AR1-iddm strain showed a high variability of the T-cells in the PBLs with a significantly lower average of the $\mathrm{CD} 3^{+} \mathrm{T}$-cell proportion. This raised the questions (1) whether the trait 'variable $\mathrm{CD}^{+}$T-cell frequency' is specific for the diabetes susceptible LEW.1AR1-iddm strain and (2) whether this trait could be mapped to a genomic region that is linked to diabetes susceptibility.

\section{The Phenotype 'variable $\mathrm{CD}^{+}$T-cell Frequency' is} Specific for the LEW.1AR1-iddm Rat Strain

LEW.1AR1-iddm rats showed a significant reduction in the average $\mathrm{CD}^{+}$T-cell frequency compared to the background

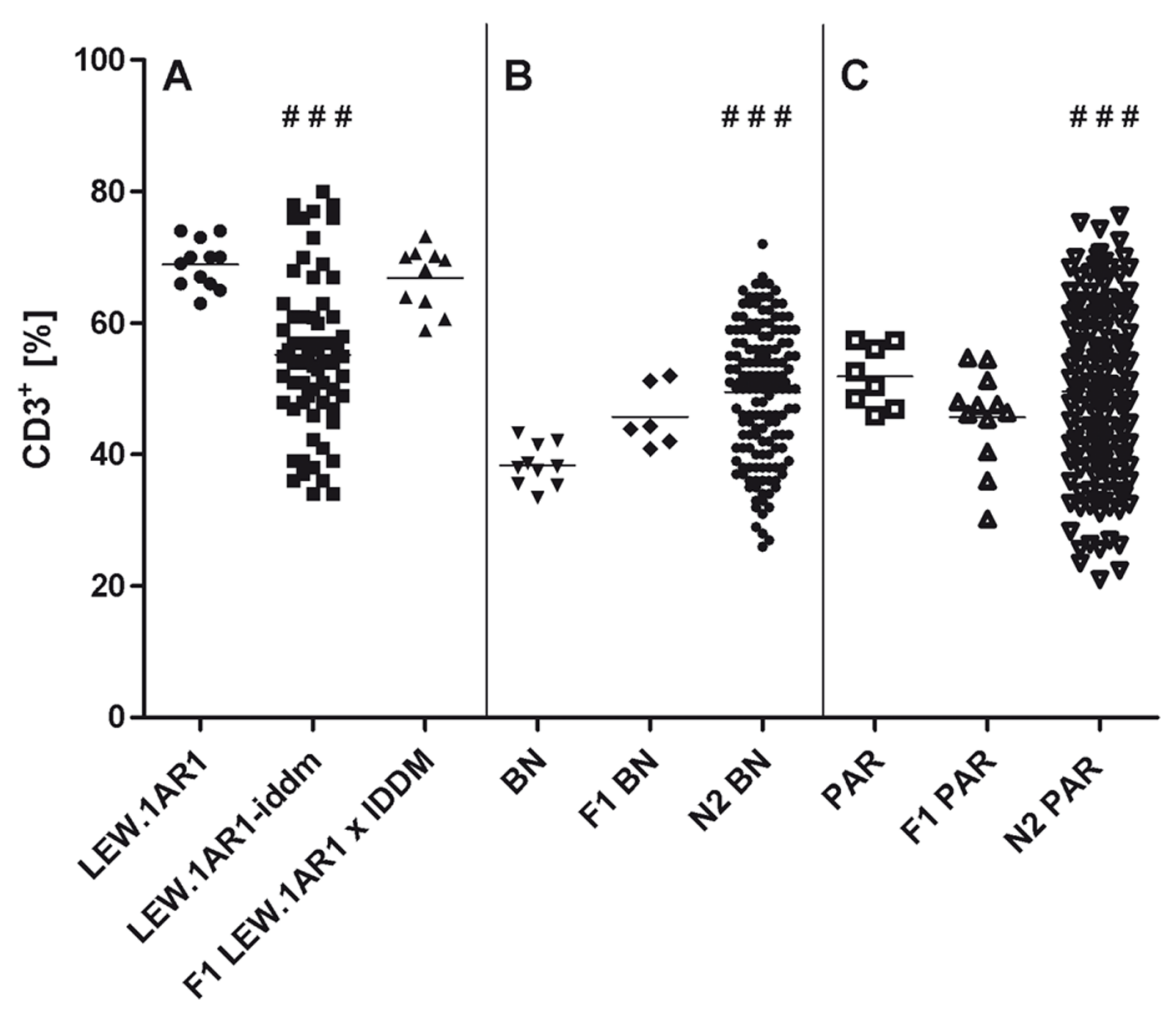

Figure 2. The percentages of $\mathrm{CD}^{+}$T-cells within PBLs of different rat strains and crosses. $\mathrm{CD} 3^{+} \mathrm{T}$-cells were measured in $\mathrm{PBLs}$ from (A) LEW.1AR1 and LEW.1AR1-iddm and the F1 populations as well as the backcross population (N2) with the (B) BN and (C) PAR strain by flow cytometric analysis at the age between 35-110 days. Each symbol represents the T-cell value for a single animal. The number of animals was for LEW.1AR1 $(n=12)$, LEW.1 AR1-iddm $(n=66)$, F1 (LEW.1 AR1 $\times$ LEW.1AR1-iddm) $(n=10), B N(n=10)$, F1 $(B N \times L E W .1 A R 1-i d d m)(n=6)$, N2 BN $(n=155)$, PAR $(n=8)$, F1 $($ PAR $\times$ LEW.1AR1-iddm) $(n=12)$, and N2 PAR $(n=151)$. The mean values for the different groups are represented by the horizontal bar in the graphs. $\# \# \# p<0.0001$ range of percentage (LEW.1AR1 group compared to LEW.1AR1-iddm group, BN group compared to N2 BN group and PAR group compared to N2 PAR group; ANOVA plus Tukey's post test).

doi:10.1371/journal.pone.0064305.g002 
A
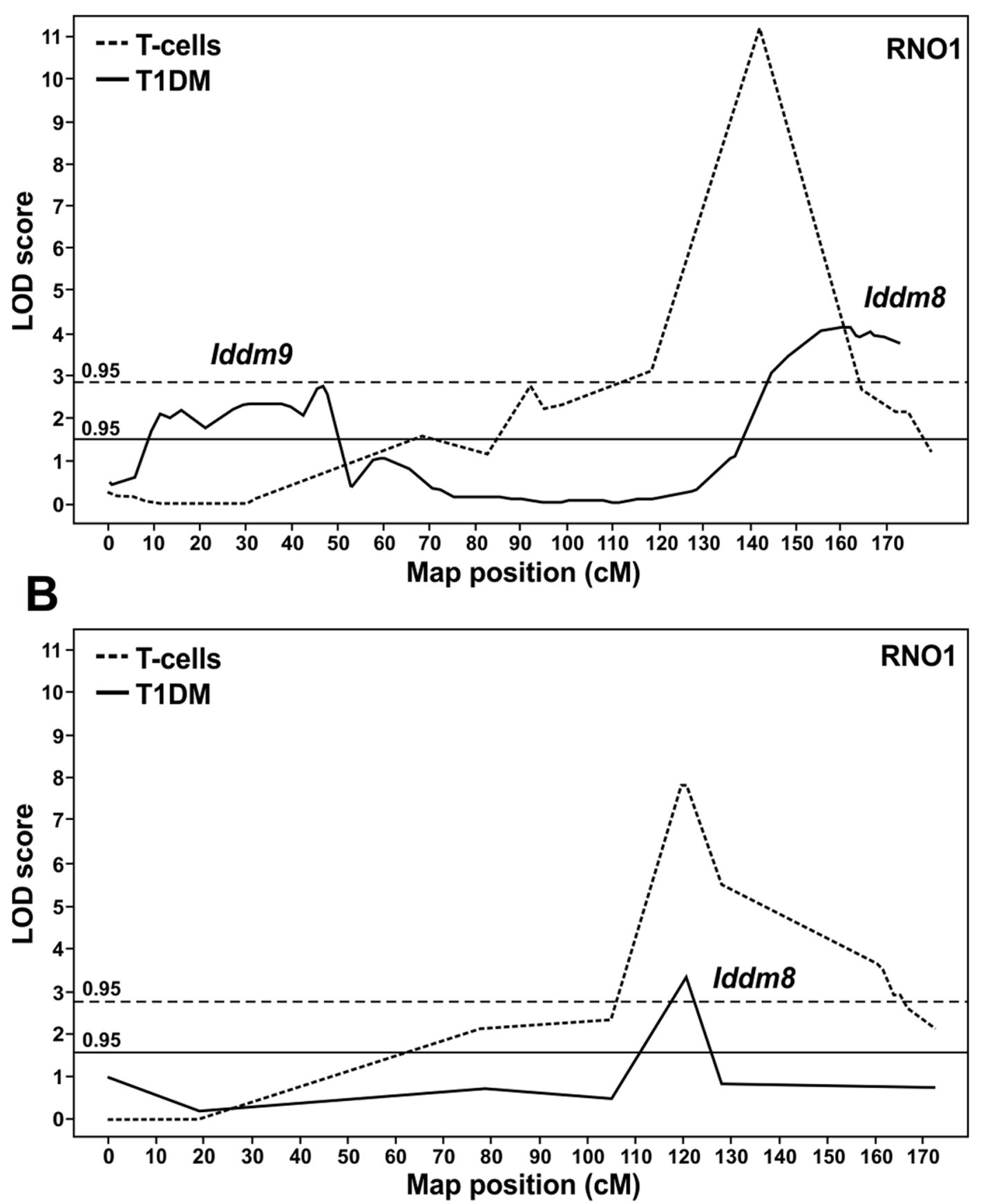

Figure 3. Association of microsatellite markers on RNO1 with the diabetes syndrome and T-cell frequency within PBLs. The LOD scores were estimated using E/M algorithms. (A) Analyses of the [(BN $\times$ LEW.1AR1-iddm) $\times$ LEW.1AR1-iddm] N2 showed a peak marker D1Ztm1 with a LOD score of 4.13 for diabetes (solid line), which was located at $162.1 \mathrm{cM} / 247.3 \mathrm{Mb}$. The variability of the T-cell frequency (dotted line) was mapped to the telomeric end of RNO1 (135 to $145 \mathrm{cM})$. The mapped locus is closely linked to Iddm8. (B) Analyses of the [(PAR $\times$ LEW.1AR1-iddm) $\times$ LEW.1AR1iddm] N2 showed a peak marker D1Ztm 17 with a LOD score of 3.9 for diabetes and is located at $120.9 \mathrm{cM} / 213.13 \mathrm{Mb}$ (solid line). The variability of the T-cells frequency (dotted line) was mapped to the telomeric end of chromosome 1 (125 to $135 \mathrm{cM}$ ). The mapped locus was closely linked to Iddm8. A permutation test considered a LOD score of $>1.5$ as significant for association with diabetes (solid line) and a LOD score of $>2.8$ as significant for association with T-cell frequency (dotted line). doi:10.1371/journal.pone.0064305.g003

strain with a great variability ranging from $34 \%$ to $80 \%$. Moreover, the $\mathrm{CD}^{+}$T-cell frequency was also significantly reduced in diabetic LEW.1AR1-iddm rats compared to the nondiabetic ones. 
It is generally accepted that a decrease of the peripheral T-cell repertoire with a particular emphasis on the $\mathrm{CD} 4^{+} / \mathrm{CD}^{+} \mathrm{T}$-cell ratio affects the balance between regulatory and effector cells and thus triggers mechanisms of autoimmunity. In the BB rat model, a pronounced reduction of all peripheral $\mathrm{T}$-cells has been reported to accompany diabetes manifestation [17-21]. In the KDP rat a mutation of the $C b l b$ gene has been described, which should affect T-cell activation but a verification of the functional relevance of this mutation has not been provided so far [22]. Interesting is also the observation that $\mathrm{CD}^{+}$and $\mathrm{CD} 4^{+} \mathrm{T}$-cells as well as the $\mathrm{CD} 4^{+}$/ $\mathrm{CD}^{+}$ratio were significantly lower in diabetic dogs [23].

In humans results of several studies indicate changes of the distribution of peripheral T-cells at diagnosis and during on-going autoimmunity when compared to healthy controls [24,25]. Interestingly, the variability of the $\mathrm{CD}^{+} \mathrm{T}$-cells was similar to that in the LEW.1AR1-iddm rat [26-29]. However, there is still controversy about the T-cell subpopulation(s) that are increased or decreased, a phenomenon that could be summarized under the term 'variability' [30-33]. In conclusion, there is consensus that changes in the T-cell distribution contribute to T1DM manifestation also in humans.

\section{Influence of Changes in T-cell Frequency on the $\mathrm{CD}^{+} /$ $\mathrm{CD}^{+}$Ratio}

Changes in the T-cell frequency of the LEW.1AR1-iddm population had a direct effect on the $\mathrm{CD}^{+} / \mathrm{CD}^{+}$ratio. A reduced ratio of $\mathrm{CD} 4^{+} / \mathrm{CD}^{+}$peripheral $\mathrm{T}$-cells found in diabetic and non-diabetic LEW.1AR1-iddm rats was mainly due to a decrease of the $\mathrm{CD} 4^{+}$T-cell number whereas the $\mathrm{CD}^{+}{ }^{+} \mathrm{T}$-cell number remained stable. Nevertheless, both $\mathrm{CD} 4^{+}$and $\mathrm{CD} 8^{+} \mathrm{T}-$ cell numbers were highly variable. Here again the variability of the $\mathrm{CD}^{+} / \mathrm{CD}^{+}$ratio within the LEW.1AR1-iddm cohort was much higher than in the background strain. Furthermore, differences between non-diabetic and diabetic animals were apparent.

In general, the ratio of $\mathrm{CD}^{+} / \mathrm{CD}^{+} \mathrm{T}$-cells is an important diagnostic marker for the function of the immune system, but the ratio varies between the strains. The background strain LEW.1AR1 had a $\mathrm{CD} 4^{+} / \mathrm{CD}^{+}$ratio of $2: 1$ while the ratio in BBDR (diabetes resistant) rats is $3: 1$ [34].

Several studies have reported an increased $\mathrm{CD} 4^{+} / \mathrm{CD}^{+}$ratio also at the onset of human T1DM, either due to a decrease in $\mathrm{CD}^{+} \mathrm{T}$-cells or an increase in $\mathrm{CD}^{+} \mathrm{T}$-cells [35-38]. However, during the prediabetic period studies found a normal or decreased $\mathrm{CD}^{+} / \mathrm{CD}^{+}$ratio $[39,40]$.

In humans an inverse $\mathrm{CD} 4^{+} / \mathrm{CD}^{+}$ratio is a sign for an acute (auto)immune response. Patients with T1DM showed a lower $\mathrm{CD}^{+} / \mathrm{CD}^{+}$ratio than healthy controls $[27,41]$. This finding is in agreement with our results in the LEW.1AR1-iddm rat. The low $\mathrm{CD} 4^{+} / \mathrm{CD}^{+}$ratio may reflect a disturbed immune balance that is primarily due to a decrease in the $\mathrm{CD}^{+}$T-cells during development of T1DM. The underlying mechanism for this imbalance is still unknown. It is, however, pivotal to know whether the variable T-cell frequency (and the concomitant change of the $\mathrm{CD}^{+} / \mathrm{CD}^{+}$ratio) are genetically inherited and linked to diabetes susceptibility.

\section{Inheritance of the Variable $\mathrm{CD}^{+} \mathrm{T}$-cell Frequency}

The analysis of the $\mathrm{CD}^{+} \mathrm{T}$-cell frequency of the two different backcross populations with the BN and PAR rat strains showed that the variable $\mathrm{CD}^{+} \mathrm{T}$-cell frequency is hereditary. In the $\mathrm{N} 2$ generation we found the same variability as in the LEW.1AR1$i d d m$ rats that led to a decrease in the $\mathrm{CD} 4^{+} / \mathrm{CD} 8^{+}$ratio.

In the human situation the $\mathrm{CD} 4^{+} / \mathrm{CD}^{+}$ratio is apparently determined by the genetic background as demonstrated in a study on adolescent twins [42]. Other studies have shown that the respective changes in $\mathrm{T}$-cell frequency are also found in nondiabetic relatives [29,43]. In addition studies in mice and men indicate that the T-cell trait appears to be under the control of a major gene $[44,45]$. Interestingly, one major trait locus for the $\mathrm{CD}^{+} / \mathrm{CD}^{+}{ }^{+}$ratio in humans is located on chromosome 11p [42]. This region is homologous to the Iddm 8 region on RNO1. Additionally, Ferreira et al. showed that there are two QTLs for the $\mathrm{CD}^{+} / \mathrm{CD}^{+}$ratio in humans [46]. One is located in MHC I and affects the $\mathrm{CD}^{+} \mathrm{T}$-cell frequency, while the second is located within the MHC II region, which causes abnormalities in the $\mathrm{CD} 4^{+} \mathrm{T}$-cell frequency.

\section{Mapping of the Variable $\mathrm{CD} 3^{+} \mathrm{T}$-cell Frequency Corresponds to Iddm8}

Through linkage analyses using microsatellite markers it was possible to identify the Iddm 8 locus within the telomeric end of RNOl as a susceptibility region not only within the BN but also in the PAR backcross population $[7,10]$. Our data clearly favour the Iddm 8 locus as the disease inducing candidate locus causing not only autoimmune diabetes but also the highly variable $\mathrm{CD}^{+} \mathrm{T}$ cell frequency with a decrease of the average $\mathrm{T}$-cell number in diabetic and non-diabetic LEW.1AR1-iddm rats.

In the $\mathrm{BB}$ rat a mutation of the Ian 5 locus is responsible for the severe loss of peripheral T-cells associated with the diabetes manifestation [47]. In the KDP rat a mutation in the Cblb gene affects $\mathrm{T}$-cell activation, thereby triggering T1DM manifestation in this model [47-49]. Notably, both these genes were unaffected in the LEW.1AR1-iddm rat (data not shown). On the other hand our data clearly indicate that the trait of 'variable $\mathrm{CD} 3^{+} \mathrm{T}$-cell frequency' maps within the $I d d m \delta$ region. This region likely codes for interesting diabetes susceptibility genes, which may have an impact on the T-cell development and function. The study does not allow a differentiation of the $\mathrm{CD} 3^{+} \mathrm{T}$-cell frequency over the lifespan but there is clear evidence that a genetically-determined variability of the peripheral $\mathrm{CD} 3^{+} \mathrm{T}$-cells can potentially cause an imbalance between regulatory and effector T-cells.

In summary, the spontaneous mutation in the LEW.1AR1-iddm rat leads not only to diabetes manifestation, but also to a highly variable $\mathrm{CD}^{+}{ }^{+} \mathrm{T}$-cell frequency and a decrease of the average $\mathrm{T}$ cell number. The mapping of the $\operatorname{Iddm} 8$ region opens the perspective to identify candidate genes for both T-cell variability and diabetes susceptibility by elucidating their interactions in triggering autoimmunity.

\section{Acknowledgments}

The technical assistance of D. Lischke, U. Sommerfeld, M. Meyer, S. Eghtessadi, I. Trotz, and S. Przyklenk is gratefully acknowledged.

\section{Author Contributions}

Conceived and designed the experiments: TA SL DW. Performed the experiments: TA HW DW. Analyzed the data: TA DW. Contributed reagents/materials/analysis tools: AJ HJH SL. Wrote the paper: TA AJ HW MT HJH SL DW. 


\section{References}

1. Bach JF (1994) Insulin-dependent diabetes mellitus as an autoimmune disease. Endocr Rev 15: 516-542.

2. Lally FJ, Bach AJ (2003) Animal models of type 1 diabetes. In: Pickup JC, Williams G, editors. Textbook of Diabetes. Oxford: Blackwell Scientific Publications

3. Lenzen S, Tiedge M, Elsner M, Lortz S, Weiss H, et al. (2001) The LEW.1AR1/ Ztm-iddm rat: a new model of spontaneous insulin-dependent diabetes mellitus. Diabetologia 44: 1189-1196.

4. Jörns A, Günther A, Hedrich HJ, Wedekind D, Tiedge M, et al. (2005) Immune cell infiltration, cytokine expression, and beta-cell apoptosis during the development of type 1 diabetes in the spontaneously diabetic LEW.1AR1/ Ztm-iddm rat. Diabetes 54: 2041-2052.

5. Arndt T, Wedekind D, Weiss H, Tiedge M, Lenzen S, et al. (2009) Prevention of spontaneous immune-mediated diabetes development in the LEW.1AR1-iddm rat by selective CD8+ $\mathrm{T}$ cell transfer is associated with a cytokine shift in the pancreas-draining lymph nodes. Diabetologia 52: 1381-1390.

6. Wedekind D, Weiss H, Jörns A, Lenzen S, Tiedge M, et al. (2005) Effects of polyinosinic-polycytidylic acid and adoptive transfer of immune cells in the LEW.1AR1-iddm rat and in its coisogenic LEW.1AR1 background strain. Autoimmunity 38: 265-275.

7. Weiss H, Bleich A, Hedrich HJ, Kölsch B, Elsner M, et al. (2005) Genetic analysis of the LEW.1AR1-iddm rat: an animal model for spontaneous diabetes mellitus. Mamm Genome 16: 432-441.

8. Pickup JC, Williams G (2003) Textbook of Diabetes 1. Oxford: Blackwell Scientific Publications.

9. Ellerman KE, Like AA (2000) Susceptibility to diabetes is widely distributed in normal class IIu haplotype rats. Diabetologia 43: 890-898.

10. Weiss H, Arndt T, Jörns A, Lenzen S, Cuppen E, et al. (2008) The mutation of the LEW.1AR1-iddm rat maps to the telomeric end of rat chromosome 1. Mamm Genome 19: 292-297.

11. Kunstýr I (1992) Diagnostic microbiology for laboratory animals. Stuttgart: Gustav Fischer Verlag.

12. Chwalisz WT, Kölsch BU, Kindler-Röhrborn A, Hedrich HJ, Wedekind D (2003) The circling behavior of the deafblind LEW-ci2 rat is linked to a segment of RNO10 containing Myo15 and Kcnj12. Mamm Genome 14: 620-627.

13. Held N, Smits BM, Gockeln R, Schubert S, Nave H, et al. (2011) A mutation in Myo15 leads to Usher-like symptoms in LEW/Ztm-ci2 rats. PLoS One 6: e15669.

14. Northrup E, Zschemisch NH, Eisenblätter R, Glage S, Wedekind D, et al. (2012) The ter mutation in the rat Dndl gene initiates gonadal teratomas and infertility in both genders. PLoS One 7: e38001.

15. Broman KW, Wu H, Sen S, Churchill GA (2003) R/qtl: QTL mapping in experimental crosses. Bioinformatics 19: 889-890.

16. Churchill GA, Doerge RW (1994) Empirical threshold values for quantitative trait mapping. Genetics 138: 963-971.

17. Bellgrau D, Naji A, Silvers WK, Markmann JF, Barker CF (1982) Spontaneous diabetes in BB rats: evidence for a $\mathrm{T}$ cell dependent immune response defect. Diabetologia 23: 359-364.

18. Guttmann RD, Colle E, Michel F, Seemayer T (1983) Spontaneous diabetes mellitus syndrome in the rat. II. T lymphopenia and its association with clinical disease and pancreatic lymphocytic infiltration. J Immunol 130: 1732-1735.

19. Jackson RA, Buse JB, Rifai R, Pelletier D, Milford EL, et al. (1984) Two genes required for diabetes in $\mathrm{BB}$ rats. Evidence from cyclical intercrosses and backcrosses. J Exp Med 159: 1629-1636.

20. Klöting I, Vogt L, Serikawa T (1995) Locus on chromosome 18 cosegregates with diabetes in the BB/OK rat subline. Diabet Metab 21: 338-344.

21. Klöting I, Kovacs P, Kuttler B (1997) Phenotypic consequences after restoration of lymphopenia in the diabetes-prone BB/OK rat. Biochem Biophys Res Commun 239: 106-110.

22. Bachmaier K, Krawczyk C, Kozieradzki I, Kong YY, Sasaki T, et al. (2000) Negative regulation of lymphocyte activation and autoimmunity by the molecular adaptor Cbl-b. Nature 403: 211-216.

23. Mori A, Sagara F, Shimizu S, Mizutani H, Sako T, et al. (2008) Changes in peripheral lymphocyte subsets in the type 1 diabetic dogs treated with insulin injections. J Vet Med Sci 70: 185-187.

24. Petersen LD, Duinkerken G, Bruining GJ, van Lier RA, de Vries RR, et al. (1996) Increased numbers of in vivo activated $T$ cells in patients with recent onset insulin-dependent diabetes mellitus. J Autoimmun 9: 731-737.

25. Roep BO (2003) The role of T-cells in the pathogenesis of Type 1 diabetes: from cause to cure. Diabetologia 46: 305-321.
26. Al-Sakkaf L, Pozzilli P, Bingley PJ, Lowdell MW, Thomas JM, et al. (1992) Early T-cell defects in pre-type 1 diabetes. Acta Diabetol 28: 189-192.

27. Faustman D, Eisenbarth G, Daley J, Breitmeyer J (1989) Abnormal Tlymphocyte subsets in type I diabetes. Diabetes 38: 1462-1468.

28. Herold KC, Huen A, Gould L, Traisman H, Rubenstein AH (1984) Alterations in lymphocyte subpopulations in type 1 (insulin-dependent) diabetes mellitus: exploration of possible mechanisms and relationships to autoimmune phenomena. Diabetologia 27 Suppl: 102-105.

29. Kaaba SA, Al-Harbi SA (1995) Abnormal lymphocyte subsets in Kuwaiti patients with type-1 insulin-dependent diabetes mellitus and their first-degree relatives. Immunol Lett 47: 209-213.

30. Legendre CM, Schiffrin A, Weitzner G, Colle E, Guttmann RD (1988) Twocolor flow cytometry analysis of activated T-lymphocyte subsets in type I diabetes mellitus. Diabetes 37: 792-795.

31. Pontesilli O, Chase HP, Carotenuto P, Herberger MJ, Hayward AR (1986) Tlymphocyte subpopulations in insulin-dependent (type I) diabetes mellitus. Clin Exp Immunol 63: 68-72.

32. Richens ER, Jones WG (1985) T-lymphocyte subpopulations in type I diabetes mellitus. A longitudinal study. Acta Diabetol Lat 22: 229-238.

33. Spooren PF, Vermes I, Soons JW (1993) Similar alterations of lymphocyte subpopulations in type I and type II diabetes. Neth J Med 42: 163-167.

34. Whalen BJ, Greiner DL, Mordes JP, Rossini AA (1994) Adoptive transfer of autoimmune diabetes mellitus to athymic rats: synergy of CD4+ and CD8+ T cells and prevention by RT6+ T cells. J Autoimmun 7: 819-831.

35. Buschard K, Ropke C, Madsbad S, Mehlsen J, Rygaard J (1983) T lymphocyte subsets in patients with newly diagnosed type 1 (insulin-dependent) diabetes: a prospective study. Diabetologia 25: 247-251.

36. Galluzzo A, Giordano C, Rubino G, Bompiani GD (1984) Immunoregulatory T-lymphocyte subset deficiency in newly diagnosed type 1 (insulin-dependent) diabetes mellitus. Diabetologia 26: 426-430.

37. Gupta S, Fikrig SM, Khanna S, Orti E (1982) Deficiency of suppressor T-cells in insulin-dependent diabetes mellitus: an analysis with monoclonal antibodies. Immunol Lett 4: 289-294.

38. Al-Sakkaf L, Pozzilli P, Tarn AC, Schwarz G, Gale EA, et al. (1989) Persistent reduction of CD4/CD8 lymphocyte ratio and cell activation before the onset of type 1 (insulin-dependent) diabetes. Diabetologia 32: 322-325.

39. Ilonen J, Surcel HM, Mustonen A, Kaar ML, Akerblom HK (1984) Lymphocyte subpopulations at the onset of type 1 (insulin-dependent) diabetes. Diabetologia 27 Suppl: 106-108.

40. Rodier M, Andary M, Richard JL, Mirouze J, Clot J (1984) Peripheral blood Tcell subsets studied by monoclonal antibodies in type 1 (insulin-dependent) diabetes: effect of blood glucose control. Diabetologia 27 Suppl: 136-138.

41. Lapolla A, Dalfra MG, Sanzari M, Fedele D, Betterle C, et al. (2005) Lymphocyte subsets and cytokines in women with gestational diabetes mellitus and their newborn. Cytokine 31: 280-287.

42. Evans DM, Zhu G, Duffy DL, Frazer IH, Montgomery GW, et al. (2004) A major quantitative trait locus for CD4-CD8 ratio is located on chromosome 11. Genes Immun 5: 548-552.

43. Peakman M, Warnock T, Vats A, McNab GL, Underhill J, et al. (1994) Lymphocyte subset abnormalities, autoantibodies and their relationship with HLA DR types in children with type 1 (insulin-dependent) diabetes and their first degree relatives. Diabetologia 37: 155-165.

44. Kraal G, Weissman IL, Butcher EC (1983) Genetic control of T-cell subset representation in inbred mice. Immunogenetics 18: 585-592.

45. Amadori A, Zamarchi R, De Silvestro G, Forza G, Cavatton G, et al. (1995) Genetic control of the CD4/CD8 T-cell ratio in humans. Nat Med 1: 12791283.

46. Ferreira MA, Mangino M, Brumme CJ, Zhao ZZ, Medland SE, et al. (2010) Quantitative trait loci for CD4:CD8 lymphocyte ratio are associated with risk of type 1 diabetes and HIV-1 immune control. Am J Hum Genet 86: 88-92.

47. Elder ME, Maclaren NK (1983) Identification of profound peripheral T lymphocyte immunodeficiencies in the spontaneously diabetic BB rat. J Immunol 130: 1723-1731.

48. Yokoi N, Kanazawa M, Kitada K, Tanaka A, Kanazawa Y, et al. (1997) A nonMHC locus essential for autoimmune type I diabetes in the Komeda DiabetesProne rat. J Clin Invest 100: 2015-2021.

49. Yokoi N, Komeda K, Wang HY, Yano H, Kitada K, et al. (2002) Cblb is a major susceptibility gene for rat type 1 diabetes mellitus. Nat Genet 31: 391-394. 